\title{
Reduction of terms of demolition works of fully assembled residential buildings in Moscow
}

\author{
Anastasiia Slavina ${ }^{1}$, Aleksej Bychkov ${ }^{1}$, German Dzhusoev ${ }^{1}$, and Margarita Borisova ${ }^{1, *}$ \\ ${ }^{1}$ Moscow State University of Civil Engineering, 26, Yaroslavskoe Shosse, Moscow, Russia
}

\begin{abstract}
As of the end of 2017, in Moscow, there are 286 mapped fivestory fully-assembled residential buildings of K-7, II-32, II-35, 1605-AM, 1MG-300 series with total area of 1046,7 thousand square meters. They were built at the beginning of the era of mass construction, in $1959-1962$ years, and were distinguished by thin outer walls of lightweight ribbed expanded clay panels with unstable thermal protection properties. The technologies used in the construction of such buildings do not allow reconstructing them. Nowadays, the task of demolition of the neighborhood of five-storey houses in Moscow with the maximum possible reduction in terms of production of works and the maximum quality of work is very important. It is also necessary to ensure safe work and compliance with all sanitary standards. The order of execution of the works has a mathematical solution method. It identifies issues that arise in the alternating sections performing the process of demolition.
\end{abstract}

\section{Introduction}

Today, five-storey "Khrushchevki" are perceived as a relic of the past, and rogue against the background of modern residential neighborhoods. But in the postwar years they were the embodiment of dreams Soviet citizens about separate apartment. Millions of families across the country huddled in basements, communal apartments and barracks-type dormitories.

In the early 1950-ies, the Federal government set the task for architects to develop projects that would expand mass housing construction. At the same time, it was necessary to achieve maximum savings in state funds [1,2].

The idea of building factories for the manufacture of components for prefabricated houses was brought from France. To reduce the cost of construction, it was decided to radically reduce all housing standards. So there was a kitchen area of 5 - 6 sq. m, combined bathroom, small adjoining room.

In 1953 there was a resolution according to which on the suburb of the capital it was supposed to create the settlement from 283 houses of the simplified type for the builders attracted to Moscow on a limit. Experimental quarter pretty quickly erected in the New Cheryomushki. The General Secretary Nikita Khrushchev liked the new neighborhood, and very soon a large construction site began all over the Union.

\footnotetext{
*Corresponding author: SlavinaAY@mgsu.ru
} 
Technology of construction of prefabricated houses was able to produce totally ready the five-storey building approximately in 45 - 50 days, while "without finishing" the building was built on average in just 12 working days, and some "stahanovtsi" (workers) at the all-Union competition set a record, by building "Khrushchevku" in five days. "Khrushchevki" were built of ready-made blocks, like a cardboard house, so the new neighborhoods grew in a matter of weeks [3].

By the beginning of 1970-ies in the country was built around 400 million square metres of five-story building. Moscow, as the flagship of panel construction, the number of new apartments on the number of residents overtook almost all major cities of the West. However, already then designers understood that life of such housing is short: for the first series of "Khrushchevok" it was about 25 years. After this time they were planned to be demolished and replaced with more durable and comfortable housing. But in fact, "Khrushchevki" continue to stand to this day, more than twice the time they spent.

The need to demolish the obsolete five-story buildings thought back in the late 1980s, but the beginning of the restructuring pushed the renovation of the housing stock to secondary roles. Active elimination of dilapidated "Khrushchevok" began only at the end of 1999, when it was signed a decree of the Moscow government "on the tasks of comprehensive reconstruction of five-storey buildings of the first period of industrial housing construction until 2010." According to this document, the residents of 1722 fivestory K-7, II-32, II-35, 1605-AM, 1MG-300 series should receive new comfortable housing by the end of 2010. The total area of demolished houses was 6 million square meters.

It is these series of houses today called "demolished". They were built at the beginning of the era of mass construction, in 1959 - 1962 years, and were distinguished by thin outer walls of lightweight ribbed expanded clay panels with insufficient thermal protection properties. The technologies used in the construction of such buildings do not allow to reconstruct them.

However, not all five-story buildings in Moscow is planned to be dismantled. "Not demolished" series include a panel "Khrushchevki" series 1-515, block - series of 1-510 and brick - series 1-511, 1-447. Such buildings have a fundamentally different design system and are designed for a longer service life.

\section{Methods}

To implement the demolition program, the so-called "wave method" was developed: first, a house is built, in which people from "Khrushchevki" move, then five-story buildings are dismantling, and new housing is being built in their place. Thus it turns out that residents move to their own area, not far from the place where they lived before. The construction complex of Moscow has developed a schedule of demolition of houses, and before the beginning of 2009, the builders, as they could, adhered to it. During this time, about $70 \%$ of the houses were dismantled. The most productive were 2006 and 2007, during which 680 five-story buildings were settled. However, then in the country began economic difficulties, resulting in a significant decrease in the rate of resettlement. In 2010, it was possible to demolish 48 houses, and in 2011 and even less -31 .

Initially, the main scope of works on renovation of blocks was carried out by construction companies on the basis of investment contracts. Developers demolished "Khrushchevki" and erected in their place, a new home, transferring to the city for the use of plots a certain percentage, which is reflected in the homes, infrastructure or payments to the budget "live" money. However after updating of the Land code implementation of all investment contracts for reconstruction of five-storeyed quarters stopped. According to the amendments that entered into force, the city authorities could no longer transfer land for the construction of starting houses without competition. In addition, not recovering from the 
economic crisis, some developers have not been able to cope with their obligations to relocate people. As a result, the city authorities made an unprecedented decision to complete the program of demolition of houses of the first period of industrial housing construction at the expense of the budget. As emphasized by the officials, this is the only solution that will allow to complete the elimination of the main part of the houses "demolished" series before the end of 2015 (Fig. 1).

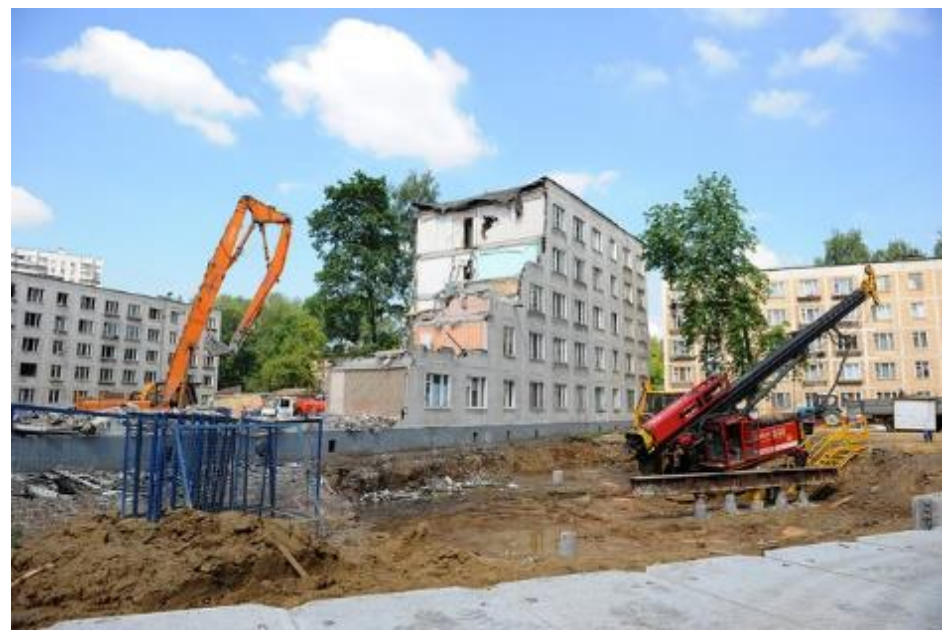

Fig. 1. The demolition of a building series K-7.

The current state of the demolition program.

As of the end of 2017286 five-storey buildings stayed in Moscow not dismantling with a total area 1046,7 thousand square meters, reported on the official website of the Moscow Department for city-planning policy of Moscow. In total, 1,722 houses of the "demolished" series were designed as part of the demolition program (Tabl. 1).

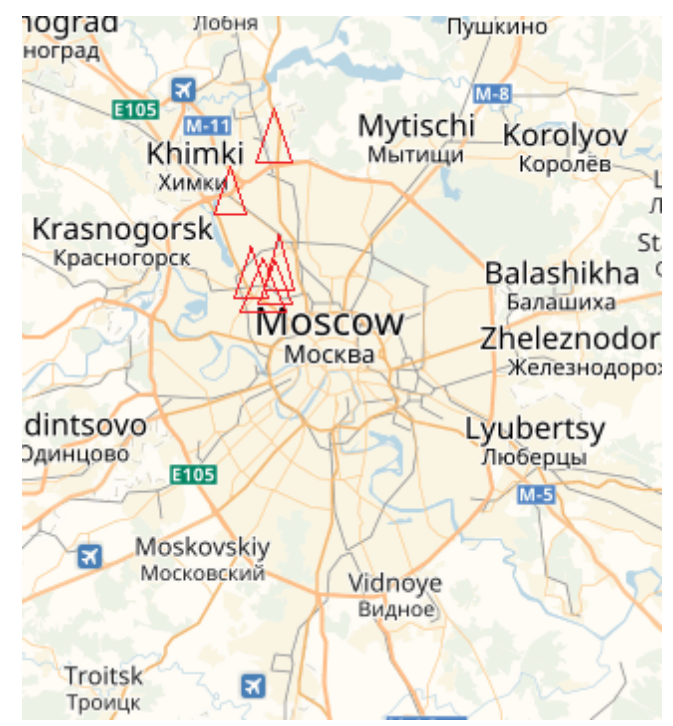

Fig. 2. Interactive map.

Only in December 2013, 9 houses were dismantled. In particular, in the North of Moscow houses at Valdai proezd, 17, Dolgoprudnaya street, 7 and 12, as well as 29 on 
Festivalnaya street were demolished. In the North-East of the capital houses 13 and 15 on Fonvizin street and houses 3, building 3-4 and housing 5 building 2 on Milashenkova street were demolished. In total, 66 dilapidated five - story buildings were demolished in Moscow in 2013, while in 2012 - 35 houses, and in 2011-31 houses. Demolition works are financed both from the city budget and under existing investment contracts. Head of the Department Sergei Levkin said that the construction on the vacated after the demolition of the territories is one of the most important directions of the program "Housing".

The program of demolition of five-storey buildings is planned to be completed in 2015: in September, an interactive map with addresses of five-storey buildings appeared on the Internet, which will be resettled and put under demolition until the end of 2015 .

\section{Results}

Problem statement.

Problem-demolition of the residential district of five-storeyed houses in the city of Moscow with the greatest possible reduction of terms of production of works and the maximum quality of works (in this case quality is characterized by convenience and the least labor input of further utilization or processing of the construction waste which remained after demolition). It is also necessary to ensure the safe production of works and the provision of all sanitary standards (in particular, noise and dust, as the work is carried out in the city).

Mathematical methods of solution.

This problem, like any task on the order of work, has mathematical methods of solving. Let's consider some of them.

The organization of the demolition by flow methods.

Continuous-flow line (CFL) is flow lines, which ensure a continuous implementation process (i.e. movement without interoperable goods wait), with continuously working workers and equipment in the workplace (i.e. work without downtime). One-subject continuous flow lines are created to perform over a long period of time, the same processes (demolition of structures) using parallel motion operations (jobs).

The advantages of parallel movement, transferred to OCFL, are continuous movement of equipment on the operations of the technological process, i.e. movement without interoperational lying and a high degree of parallelism of all processes, leading to a reduction in the terms of demolition and minimizing the volume of work in progress. One of the drawbacks of parallel movement is the piece-by-piece transfer (transfer in small batches) of sections simultaneously between all working tools. The second shortcoming the presence of interruptions in the workplace-requires the use of special methods of synchronization operations.

Synchronization, using the principle of proportionality, involves equalizing the duration of all operations with the rhythm of the line. Thus, full and uniform loading of line workplaces is achieved. Analytically, the synchronization condition is written as follows (1):

$$
\mathrm{t}_{\mathrm{br}}^{\mathrm{j}}=\mathrm{r}_{\mathrm{lr}}-\frac{\mathrm{t}_{\mathrm{j}}}{\mathrm{q}_{\mathrm{j}}} \Rightarrow 0 ; \mathrm{j}=1, \ldots, \mathrm{K}_{\mathrm{op}}
$$

where $\mathrm{t}_{\mathrm{br}}^{\mathrm{j}}$ - a break that occurs in the operation after each operation of the demolition; $t_{j}$ - piece time of the $j$-th operation;

$\mathrm{q}_{\mathrm{j}}$ - number of jobs per operation $\mathrm{j}$;

$\mathrm{r}_{\mathrm{lr}}$ - the rhythm of the line.

Hence, the calculated number of jobs per $q_{j}$ operation is determined as follows (2): 


$$
q_{j}=\frac{t_{j}}{r_{l r}} ; j=1, \ldots, K_{o p}
$$

The accepted number of jobs $q_{j}^{p r}$ is determined by rounding up to the nearest whole number. Thus, the process of ensuring equality or multiplicity of the duration of all operations to the rhythm of the production line is the essence of synchronization. This provides equalization of performance for all operations flow.

Distinguish between the preliminary (in the design of flow lines) and final synchronization (when debugging FL in the conditions of the site). Pre-synchronization allows a deviation of $\pm 10 \%$ in the duration of the operation from the rhythm, which must be eliminated to the maximum extent possible with the final synchronization. The synchronization methods are:

- splitting or merging operations;

- the combination of various variants of execution order of transitions and their regrouping in the new operation;

- concentration of operations, combining the time of several transitions with the use of aggregated means of technological equipment;

- intensification of operating modes;

- the combination of time machine and hand work;

- rationalization of working methods, etc.

Rhythm is a fundamental characteristic in the calculation of any flow lines. It is determined by the mode of operation of the line (number of working days, shifts, hours, duration of the regulated breaks), i.e. by the fund of its time of work $\mathrm{F}$ and the program of release of products $\mathrm{N}_{B}$ for the same period: $r_{l r}=F / N_{B}$. In the recording of the synchronization condition, the rhythm is analogous to the main time when the movement is parallel.

Multi-product flow lines.

On multi-product flow lines, several types of processes are executed alternately or mixed. In the first case, they are performed alternately, so the essential feature is the presence or absence of equipment changeover when changing the site of work. On this basis distinguish variably in-line (sequentially, batch) and group multi-disciplinary streams. The fact that multi-product streams combine all the advantages of mass production with a sufficient degree of flexibility, allows to consider them as the most promising branch of development of mass production.

Multi-product flow line with sequence-batch alternating items, or variable-flow, is the line which is used to execute the processes of various kinds alternating in time batches, alternating on all operations simultaneously or over a relatively short period of time. Every time this line is executed the process only to any one name, except for the period of the change the station. To move to the next process type, you need to reconfigure the hardware. During the execution of processes of one name, the variable-flow line works as a single-line continuous (OCFL) or discontinuous (ODFL), depending on the synchronization of operations. Execution of demolition operations with a variable-flow line is not a single rhythm, and in accordance with the particular rhythms. A particular rhythm is the average equal time interval through which the processes of the corresponding name must be performed.

Typically, variable-flow lines are assigned from 2 to 10 process names with approximately the same execution technology. To change sections, the total number of jobs on the operations of the line have not been changed, you must distribute the fund operating time line for the period proportionally to the complexity of implementation of the processes of demolition (3): 


$$
F_{i}=\frac{F_{e f} N_{p}^{i} T_{p}^{i}}{\sum_{i=1}^{K_{B}} N_{p}^{i} T_{p}^{i}},
$$

Then the private rhythm $r_{i}$. will be determined by the formula (4):

$$
r_{i}=\frac{F_{e f} T_{p}^{i}}{\sum_{i=1}^{K_{B}} N_{p}^{i} T_{p}^{i}}
$$

where $\mathrm{F}_{\mathrm{ef}}$ - effective fund operating time lines on the planning horizon, hours,

$\mathrm{N}_{\mathrm{p}}^{\mathrm{i}}$ - program executing processes of the i-th name in the same period.;

$\mathrm{T}_{\mathrm{p}}^{\mathrm{i}}$ - the sum of the norms of the piece time of the processes of the $\mathrm{i}$-th name for all operations of the line, hours.

If it is possible to find sites with approximately equal duration of performance of technological operations of demolition, such line can work with a uniform rhythm for all sites (5):

$$
\mathrm{r}_{\mathrm{lr}}^{\mathrm{m}}=\frac{\mathrm{F}_{\mathrm{ef}}\left(1-\mathrm{K}_{\mathrm{per}}\right)}{\sum_{\mathrm{i}=1}^{\mathrm{K}_{\mathrm{B}}} \mathrm{N}_{\mathrm{p}}^{\mathrm{i}}},
$$

Moreover, to ensure the equality of all private rhythms, it is necessary to allocate the total fund of the line operation time between the sections according to a different principle — in proportion to the amount of work (6).

$$
F_{i}=\frac{F_{e f} N_{p}^{i}}{\sum_{i=1}^{K_{B}} N_{p}^{i}}
$$

\section{Conclusions}

Notice that we still need to strive for equality of private rhythms. An ideal MNPL organization involves end-to-end synchronization, synchronizing operations when all the processes assigned to the line are performed. This can significantly reduce the time spent on its relocation by maintaining the constant values of the leading characteristics. Because in every moment of time variable continuous production line performed the process of demolition only of any one denomination, its operation is different from the organization of CFL, the complication is associated only with the process of alternation sites. Here there are several problems:

1) organization of change of production sites on the line;

2) providing the possibility of demolition of structures with similar demolition process maps;

3) determination of the optimal order of the start of demolition processes at different sites.

\section{References}

1. M. Ershov, G. Gamreklidze, A. Mamin, Technology and organization of construction production 4-1(9) (2015)

2. P. Oleynik, S. Sinenko, B. Zhadanovsky, V. Brodsky, M. Kuzhin, MATEC Web of Conferences 86 (2016) doi:10.1051/matecconf/20168604059

3. B. Zhadanovsky, A. Beschastyi, Mechanical processing of diamond tools by nonmetallic materials and reinforced concrete in construction (Moscow, 2017) 